\title{
Cancer mortality in England in relation to levels of naturally occurring fluoride in water supplies
}

\author{
CLAIR CHILVERS ${ }^{1}$ AND DEIRDRE CONWAY² \\ From the Section of Epidemiology, ${ }^{1}$ Institute of Cancer Research, Block D, Clifton Avenue, Sutton, Surrey SM2 \\ 5PX and Water Research Centre, ${ }^{2}$ Henley Road, Medmenham, PO Box 16, Marlow, Bucks SL7 2DH
}

SUMMARY Sixty-seven small areas in England have been classified into four groups according to the level of naturally occurring fluoride in their water supplies. Small area mortality statistics for 1969-73 have been used to look for differences in cancer mortality in relation to fluoride levels. Deaths from all cancers and from cancer at 12 specific body sites have been examined; no consistent trends in mortality are apparent. These results provide no evidence of a harmful effect of naturally occurring fluoride in water supplies.

A number of recent studies have searched for but failed to find an association between fluoride in water supplies and an increased risk of cancer. ${ }^{1-4}$ These studies have, however, all dealt with artificially fluoridated water supplies, and there is advantage in investigating naturally occurring fluoride and cancer mortality or incidence, as did a number of earlier studies in the United States and Britain,,$^{5-9}$ since the populations have generally been exposed for considerably longer. The morbidity study carried out by Kinlen ${ }^{9}$ is of particular interest among the British studies of naturally occurring fluoride because cancer incidence data were available for small areas and allowed more satisfactory comparisons between relatively high and low fluoride areas than had been the case with earlier mortality studies. More recently, however, mortality statistics for small areas for the five years around the 1971 census have become available, and the results of a study using these data are reported here.

\section{Methods}

Naturally occurring fluoride is classified here as follows: 'high' $1.0 \mathrm{ppm}$ or more, 'medium' 0.5-0.99 ppm, 'low' $0.2 \mathrm{ppm}$ or less, and 'very low' $0.1 \mathrm{ppm}$ or less. As a starting point the areas used by Kinlen' were investigated. The fluoride levels in those areas were checked for consistency with other available data. Particular attention was given to the weighting of concentrations with regard to quantities supplied; where more than one water source supplied a local authority area a weighted mean was calculated using weights based on the time period 1950-72. On this basis some of the areas used by Kinlen ${ }^{9}$ appeared to be misclassified and were therefore excluded, but information was available for some additional areas $f$ that were added. Each high area was matched with a 응 low area, and each medium area with a very low area $\stackrel{\complement}{\Omega}$ Areas were matched for urban/rural status and, as fap as possible, for population size; in two of the 32 pairso of areas, however, the population size differed by a factor of two. As far as possible the areas were chosen to be geographically close but frequently suitablecontrol areas close by could not be found; the furthest apart were approximately 85 miles. The areas used are listed in the Appendix.

The sites of cancer chosen for study (Table 1) were based on those investigated by Kinlen, ${ }^{9}$ to which were added other common cancers (lung and ovary), and those found by other workers to show interesting trends (buccal cavity and pharynx, skin). For completeness, the pancreas as part of the gastrointestinal tract and all cancers together were included.

Table 1 Sites of cancer

\begin{tabular}{ll}
\hline ICD (8th Revision) & Site \\
\hline $140-209$ & All cancers \\
$140-149$ & Buccal cavity and pharynx \\
150 & Oesophagus \\
151 & Stomach \\
$152-3$ & Intestine \\
154 & Rectum \\
157 & Pancreas \\
162 & Lung \\
$172-3$ & Skin \\
174 & Breast \\
183 & Ovary \\
188 & Bladder \\
189 & Kidney and other urinary \\
\hline
\end{tabular}


Standardised mortality ratios (SMRs) and numbers of deaths (D) for 1969-73, the five-year period centred on the 1971 census, for males and females separately, in each of the 67 study areas were obtained from microfiche tables supplied by the Office of Population Censuses and Surveys. ${ }^{10}$ In order to calculate SMRs for each of the four fluoride groups (high, medium, low, and very low) the expected number of deaths (E) over the five-year period in each area was calculated:

$$
\left(E=\frac{100 \times D}{S M R}\right) .
$$

Where no deaths occurred in an area, the expected number of deaths in that area was not available from the microfiche tables but was calculated by applying England and Wales age-sex-specific death rates ${ }^{11}$ to the population age structure of that area. ${ }^{10}$

In each fluoride group, observed and expected deaths were summed over all the areas in that group to give the total deaths observed ( $\Sigma D)$ and total deaths expected $(\Sigma E)$ in each group; the SMR for each group can then be calculated $(100 \times \Sigma D / \Sigma E)$. This procedure was carried out for 10 sites of cancer for males, 12 sites for females, and for all sites of cancer taken together (table 1).

In view of the matching, only comparisons of high with low and medium with very low fluoride areas are valid for each cause of death. A conventional test of significance based on the normal distribution was used. ${ }^{12}$

\section{Results}

Standardised mortality ratios (SMRs) and numbers of deaths from each site of cancer are shown in table 2 . SMRs for all sites of cancer taken together in the high and low fluoride areas were similar: for males 95 and 97 and for females 96 and 99 in the high and low fluoride areas respectively. The male SMR for all sites was higher in the very low fluoride areas (SMR 96) than in the medium fluoride areas (SMR 89), $(p<0.05)$. For only three sites of cancer were there statistically significant differences in SMRs, but in each case these differences were for either males or females but not for both. For two sites the higher SMR occurred in the lower fluoride areas; the male SMR for rectal cancer was 131 in low fluoride areas compared with 89 in high areas, and the male SMRs for bladder cancer were 80 and 107 in medium and very low fluoride areas respectively. However, for cancers of the buccal cavity and pharynx mortality was higher in the high fluoride areas (SMR 121) than in the low areas (SMR 65). In somewhat more than half the comparisons ( 29 out of 44 ) the SMR was lower in the group of areas with the higher level of fluoride.

\section{Discussion}

The major advantage of studying populations exposed to naturally occurring fluoride rather than those living in areas with artificially fluoridated water

Table 2 Cancer mortality in areas with differing levels of naturally occurring fluoride in their water supplies: SMRs (numbers of deaths), 1969-73

\begin{tabular}{|c|c|c|c|c|c|}
\hline \multirow{2}{*}{ Cancer } & \multirow{2}{*}{ Sex } & \multicolumn{4}{|c|}{ Fluoride levels } \\
\hline & & High & Low & Medium & Very low \\
\hline All & $\begin{array}{l}\mathbf{M} \\
\mathbf{F}\end{array}$ & $\begin{array}{l}95 \cdot 06(2426) \\
96 \cdot 36(2039)\end{array}$ & $\begin{array}{l}97.06(2255) \\
98.58(1957)\end{array}$ & $\begin{array}{r}* 89.02(2525) \\
97.18\end{array}$ & $95.55(2632)$ \\
\hline Buccal cavity & $\mathbf{M}$ & $102.97(41)$ & $116.69(42)$ & $\begin{array}{l}97 \cdot 18(2169) \\
97 \cdot 57(43)\end{array}$ & $97.92(2236)$ \\
\hline and pharynx & $\mathbf{F}$ & ${ }^{*} 120.91(30)$ & $64.92(15)$ & $\begin{array}{l}97.57(43) \\
81.00(21)\end{array}$ & $\begin{array}{l}77.08(33) \\
79.00(21)\end{array}$ \\
\hline \multirow[t]{2}{*}{ Oesophagus } & $\mathbf{M}$ & $86.86(60)$ & $84 \cdot 56(53)$ & $75 \cdot 56(58)$ & $104 \cdot 76(78)$ \\
\hline & $\mathbf{F}$ & $81 \cdot 19(44)$ & $108 \cdot 10(54)$ & $90.02(50)$ & $100 \cdot 33(58)$ \\
\hline \multirow[t]{2}{*}{ Stomach } & $\mathbf{M}$ & $97.88(288)$ & $88.07(234)$ & $85 \cdot 10(275)$ & $90 \cdot 26(284)$ \\
\hline & $F$ & $82 \cdot 80(177)$ & $89.39(175)$ & $83.09(180)$ & $94.43(214)$ \\
\hline \multirow[t]{2}{*}{ Intestine } & $\mathbf{M}$ & $93.51(162)$ & $113 \cdot 14(177)$ & $94 \cdot 21(180)$ & $101.62(189)$ \\
\hline & $F$ & $93.82(230)$ & $97.69(221)$ & $104.94(264)$ & $105.90(277)$ \\
\hline \multirow[t]{2}{*}{ Rectum } & $\mathbf{M}$ & ${ }^{*} 89.11(115)$ & $131 \cdot 86(153)$ & $93.52(133)$ & $103 \cdot 26(143)$ \\
\hline & $F$ & $93.49(103)$ & $94.43(96)$ & $101 \cdot 23(114)$ & $99.64(117)$ \\
\hline \multirow[t]{2}{*}{ Pancreas } & $\mathbf{M}$ & $108 \cdot 02(119)$ & $82.02(82)$ & 90.07 (110) & $89.40(106)$ \\
\hline & $\mathrm{F}$ & $108 \cdot 70(106)$ & $89.08(80)$ & $107.04(107)$ & $83.90(87)$ \\
\hline \multirow[t]{2}{*}{ Lung } & $\mathbf{M}$ & $92.97(938)$ & $91.01(841)$ & $87.71(984)$ & $94.80(1035)$ \\
\hline & $\mathrm{F}$ & $97.71(214)$ & $88 \cdot 21(181)$ & $95.41(221)$ & $87.47(207)$ \\
\hline \multirow[t]{2}{*}{ Skin } & $\mathbf{M}$ & $97.59(19)$ & $120 \cdot 79(22)$ & $93.96(21)$ & $107 \cdot 15(23)$ \\
\hline & $F$ & $142 \cdot 81(30)$ & $129 \cdot 32(26)$ & $69.98(16)$ & $108 \cdot 10(25)$ \\
\hline \multirow[t]{2}{*}{ Bladder } & $\mathbf{M}$ & $96.48(110)$ & $98 \cdot 79(100)$ & *79.78 (99) & $106 \cdot 63(129)$ \\
\hline & $\mathrm{F}$ & $88.67(41)$ & $117 \cdot 54(50)$ & $95.93(45)$ & $95.53(47)$ \\
\hline \multirow{2}{*}{ Kidney } & $\mathbf{M}$ & $102 \cdot 11(38)$ & $77 \cdot 51(27)$ & $65 \cdot 85(28)$ & $100 \cdot 23(41)$ \\
\hline & $F$ & $102.07(25)$ & 83.09 (19) & $108 \cdot 75(28)$ & $114 \cdot 39(30)$ \\
\hline Breast & $F$ & $96 \cdot 78(410)$ & $98 \cdot 13(396)$ & $105 \cdot 47(483)$ & $101.66(470)$ \\
\hline Ovary & $\mathrm{F}$ & $98.73(136)$ & $118.72(156)$ & $100 \cdot 39(150)$ & $86.43(130)$ \\
\hline
\end{tabular}


supplies is that many years' exposure will have accumulated in naturally fluoridated areas. This is particularly important when considering cancer where a long latent period between first exposure to a carcinogen and development of the cancer is common.

Mortality data are more complete than registration data but suffer from two disadvantages. Where survival is good, for example, breast cancer, they reflect incidence many years previously, and only approximately if death commonly occurs from other causes. However, for those causes where survival is poor, for example, lung cancer and stomach cancer, such data are both reliable and widely used. ${ }^{13}$

Two mortality studies of areas with differing levels of naturally occurring fluoride have been carried out in England and Wales. Heasman and Martin ${ }^{7}$ compared mortality from a number of causes including cancer in 18 high fluoride areas with control areas $(<0.2 \mathrm{ppm} F)$. Stomach cancer mortality appeared to be higher in the higher fluoride areas (SMR 109 compared with 101 in control areas) but they concluded that this difference was unlikely to be due to fluoride. Nixon and Carpenter ${ }^{8}$ reanalysed Heasman and Martin's data taking account of water hardness and socioenvironmental variables. They studied all cancers and included stomach cancer among 'stomach diseases'. Their conclusion was that if naturally occurring fluoride has any effect on mortality it is likely to be beneficial.

Two studies from the United States report comparisons of areas with differing levels of naturally occurring fluoride. Hagan et $l^{6}$ paired 32 cities, each with at least $0.7 \mathrm{ppm}$ fluoride in their water supplies, with control cities ( $\leqslant 0.25 \mathrm{ppm}$ fluoride). All-cancer mortality rates standardised for age and sex were compared in each pair of cities: 16 pairs had higher mortality in the city with the higher fluoride level, and in the other 16 pairs the converse was true. Hoover $e a^{5}$ studied site specific cancer mortality in Texas counties classified by fluoride levels into four groups. Consistent trends were found for cancers of the buccal cavity and pharynx (males only), oesophagus (males and females), and skin (females only). All these trends were in the opposite direction to that of fluoride level. Multiple regression analysis revealed a statistically significant negative association with the fluoride variable in four out of 64 tests of significance.

In Kinlen's ${ }^{9}$ study of cancer incidence, formal tests of significance were not carried out, but from the data available statistically significant differences at the 0.05 level can be shown only for breast cancer. The direction of the trends was, however, inconsistent in the two comparisons made. The areas used by Kinlen differ somewhat from ours, and he used registry data for the years 1961-8.

No consistent trends are apparent in our data. Only three statistically significant differences were found in 44 tests, and no allowance has been made in the significance levels quoted for the multiple tests of significance that have been carried out. As a rough estimate, one might have expected to find two out of 44 statistically significant results at the $5 \%$ level in the mortality study if there were no association with fluoride level. Given the lack of theoretical grounds for expecting an effect of fluoride on cancer, and the likelihood that the statistically significant results found here could have arisen by chance, there seems to be no reason for further study of these small areas. The present results do, however, provide further evidence for rejecting the claims of a harmful effect of fluoridation.

We thank Dr Leo Kinlen for allowing us access to his correspondence with water authorities, Hazel Fox for meticulous computer programming, and Doreen Folkes for preparing the manuscript. Clair Chilvers was financed by the Cancer Research Campaign and by a grant from the Department of Health and Social Security.

\section{References}

${ }^{1}$ Kinlen L, Doll R. Fluoridation of water supplies and cancer mortality. III: A re-examination of mortality in cities in the USA. J Epidem Comm Hlth, 1981; 35: 239-44.

${ }^{2}$ Chilvers C. Cancer mortality by site and fluoridation of water supplies.J Epidem Comm Hlth, 1982; 36: 237-42.

${ }^{3}$ Chilvers C. Cancer mortality and fluoridation of water supplies in 35 US cities. Int $J$ Epidem, 1983; 12: $397-404$.

${ }^{4}$ Cook-Mozzaffari P, Doll R (1981). Fluoridation of water supplies and cancer mortality. II: Mortality trends after fluoridation. J Epidem Comm Hlth, 1981; 35: 233-8.

${ }^{5}$ Hoover RN, McKay FW, Fraumeni JF Jr. Fluoridated drinking water and the occurrence of cancer. $J$ Nat Cancer Inst, 1976; 57: 757-60.

${ }^{6}$ Hagan TL, Pasternack M, Scholz GC. Waterborne fluorides and mortality. Public Health Reports, 1954; 69: $(1-12): 450-4$.

${ }^{7}$ Heasman MA, Martin AE. Mortality in areas containing natural fluoride in their water supplies. Mon Bull Minist Hlth, 1964; 21: 150-61.

${ }^{8}$ Nixon JM, Carpenter RG. Mortality in areas containing natural fluoride in their water supplies, taking account of socio-environmental factors and water hardness. Lancet, 1974; ii: 1068-71.

${ }^{9} \mathrm{~K}$ inlen L. Cancer incidence in relation to fluoride level in water supplies. Comm Hlth, 1974; 6: 69-74.

${ }^{10}$ Office of Population Censuses and Surveys. Area mortality tables 1969-73. Urban and rural supplements. 1982. 
${ }^{11}$ Office of Population Censuses and Surveys. Area mortality tables 1969-73. Series D S No. 3. 1979.

${ }^{12}$ Office of Population Censuses and Surveys. Area mortality 1969-73. Series DS No. 4. London: HMSO, $1981 ; 9$.

${ }^{13}$ Davies JM, Chilvers C. The study of mortality variations in small administrative areas of England and Wales, with special reference to cancer.J Epidem Comm Hlth, 1980; 34: 87-92.

\section{Appendix_Areas studied}

(a) High fluoride areas ( $F \geqslant 1.0 \mathrm{ppm}$ ) and low fluoride controls ( $F \leqslant 0.2 \mathrm{ppm})$

\begin{tabular}{ll}
\hline Local authority & $\begin{array}{l}\text { Fluoride level }(p p m) \\
1950-72 \text { unless } \\
\text { otherwise stated }\end{array}$ \\
& $>1 \cdot 0$ \\
\hline West Hartlepool CB and & $0 \cdot 1-0 \cdot 3$ \\
Hartlepool MB & $>1 \cdot 0$ \\
Darlington CB* & $0 \cdot 14-0 \cdot 20$ \\
Colchester MB & $\geqslant 1 \cdot 0$ \\
Cambridge MB & $<0 \cdot 2$ \\
Harwich MB & $>1 \cdot 0$ \\
Hertford MB & $0 \cdot 2$ \\
Braintree UD & $\geqslant 1 \cdot 0$ \\
Bury St Edmunds MB & $<0 \cdot 2$ \\
Brightlingsea UD & $1950-70 \quad 4 \cdot 0-5 \cdot 0$ \\
Baldock UD & $1971-73 \quad 0 \cdot 16-0 \cdot 28$ \\
Burnham on Crouch UD & $<0 \cdot 2$ \\
& $\geqslant 1 \cdot 0$ \\
Royston UD & $<0 \cdot 2$ \\
Clacton UD & $\geqslant 1 \cdot 0$ \\
Hitchin UD & $0 \cdot 1$ \\
Frinton \& Waldon UD & $1 \cdot 4$ \\
Newmarket UD & $0 \cdot 2$ \\
West Mersea UD & $\geqslant 1 \cdot 0$ \\
Sudbury MB & $0 \cdot 1$ \\
Wivenhoe UD & $1 \cdot 0$ \\
Aldeburgh MB & $<0 \cdot 2$ \\
Lexden \& Winstree RD & $1 \cdot 0$ \\
Hitchin RD & $<0 \cdot 2$ \\
Tendring RD & $1950-67 \geqslant 1 \cdot 1$ \\
South Cambridgeshire RD & $1968-720 \cdot 8$ \\
Brackley MB & $<0 \cdot 2$ \\
Chipping Norton MB & \\
\hline
\end{tabular}

*The only suitable control within reasonable distance (b) Medium fluoride areas ( $F=0.5-0.99 \mathrm{ppm})$ and very low fluoride controls $\cdot F \leqslant 0 \cdot 1 \mathrm{ppm})$

\begin{tabular}{|c|c|}
\hline Local authority & $\begin{array}{l}\text { Fluoride level (ppm) } \\
1950-72 \text { unless } \\
\text { otherwise stated }\end{array}$ \\
\hline $\begin{array}{l}\text { Heanor UD } \\
\text { Bolsover UD }\end{array}$ & $\begin{array}{l}0.65 \\
<0.1\end{array}$ \\
\hline Maldon MB & $\begin{array}{l}0.6-1 \cdot 0, \text { with small area of } \\
\text { town receiving } 3.0\end{array}$ \\
\hline Kings Lynn MB & $0 \cdot 1$ \\
\hline $\begin{array}{l}\text { Halstead UD } \\
\text { March UD }\end{array}$ & $\begin{array}{l}0.9 \\
<0.1\end{array}$ \\
\hline $\begin{array}{l}\text { Dunmow RD } \\
\text { Horsham RD }\end{array}$ & $\begin{array}{l}0.5-0.65 \\
<0.1\end{array}$ \\
\hline $\begin{array}{l}\text { Braintree RD } \\
\text { Wisbech RD }\end{array}$ & $\begin{array}{l}>0.5 \\
<0.1\end{array}$ \\
\hline $\begin{array}{l}\text { Cromer UD } \\
\text { Chatteris UD }\end{array}$ & $\begin{array}{l}0.5-0.75 \text { (seasonal) } \\
<0.1\end{array}$ \\
\hline $\begin{array}{l}\text { Hadleigh UD } \\
\text { Downham Market UD }\end{array}$ & $\begin{array}{l}0.65-0.8 \\
<0.1\end{array}$ \\
\hline $\begin{array}{l}\text { Woodbridge UD } \\
\text { Hunstanton UD* }\end{array}$ & $\begin{array}{l}0 \cdot 6 \\
0 \cdot 15\end{array}$ \\
\hline $\begin{array}{l}\text { Wimborne Minster UD } \\
\text { Wareham MB }\end{array}$ & $\begin{array}{l}1950-690.6-0.7 \\
<0.1\end{array}$ \\
\hline $\begin{array}{l}\text { Swindon MB } \\
\text { Bath CB }\end{array}$ & $\begin{array}{l}0.6-1 \cdot 1 \\
<0 \cdot 1\end{array}$ \\
\hline $\begin{array}{l}\text { Chippenham MB } \\
\text { Winchester MB }\end{array}$ & $\begin{array}{l}0.6-1 \cdot 1 \\
<0.1\end{array}$ \\
\hline $\begin{array}{l}\text { Staveley UD } \\
\text { Kirkburton UD }\end{array}$ & $\begin{array}{l}0 \cdot 5-1 \cdot 0 \\
0 \cdot 1\end{array}$ \\
\hline $\begin{array}{l}\text { Clowne RD } \\
\text { Stone RD }\end{array}$ & $\begin{array}{l}0.5-1.0 \\
<0.1\end{array}$ \\
\hline $\begin{array}{l}\text { Ilkeston MB } \\
\text { Worksop MB }\end{array}$ & $\begin{array}{l}>0.5 \\
<0.1\end{array}$ \\
\hline $\begin{array}{l}\text { East Dereham UD } \\
\text { Wymondham UD }\end{array}$ & $\begin{array}{l}0.5 \\
<0.05\end{array}$ \\
\hline $\begin{array}{l}\text { Gipping RD } \\
\left\{\begin{array}{l}\text { St. Neots RD } \\
\text { Huntingdon RD }\end{array}\right.\end{array}$ & $\begin{array}{l}0.7-0.9 \\
0.1 \\
0.1\end{array}$ \\
\hline $\begin{array}{l}\text { Bradford \& Melksham RD } \\
\text { Lydney RD }\end{array}$ & $\begin{array}{l}0 \cdot 7 \\
\leqslant 0 \cdot 1\end{array}$ \\
\hline $\begin{array}{l}\text { Ripon \& Pateley Bridge RD } \\
\text { Howden RD }\end{array}$ & $\begin{array}{l}0 \cdot 0-1 \cdot 3 \text {, mean } 0.99 \\
\leqslant 0 \cdot 1\end{array}$ \\
\hline $\begin{array}{l}\text { Wokingham RD } \\
\left\{\begin{array}{l}\text { Hungerford RD } \\
\text { Amesbury RD }\end{array}\right.\end{array}$ & $\begin{array}{l}1950-75 \text { mean } 0.89 \\
\leqslant 0.1 \\
\leqslant 0 \cdot 1\end{array}$ \\
\hline
\end{tabular}

*The only suitable control within reasonable distance 